\title{
Investigating waste reduction potential in the upstream processes of offshore prefabrication construction
}

Dr. Weisheng $\mathrm{Lu}^{1}$ and Dr. Hongping Yuan ${ }^{2}$

\begin{abstract}
The construction industry around the globe has been increasingly advocated to utilize prefabrication to minimize waste, thereby alleviating associated negative impacts on environment and the society. Previous studies have reported on waste reduction potential from adopting prefabrication in various economies including Hong Kong. A significant shortcoming of these studies, however, is the neglect of the upstream processes of prefabrication including the manufacturing and transportation of components, which causes construction waste as well. To date it is still unclear how this portion of construction waste is generated and quantified. The issues are even more complicated in Hong Kong where components are manufactured in the offshore Pearl River Delta Region (PRDR) of mainland China and transported across the border to construction sites in Hong Kong. Against the theoretical backdrop of whole life cycle thinking, the aim of this study is to empirically investigate the manufacture and cross-border transportation processes, thereby to assess the waste reduction potentials of using prefabrication in construction. It does so by conducting three in-depth case studies with selected PRDR prefabrication factories. A hybrid of research methods are employed in the study. It is found that the waste generation rate in the upstream processes of offshore prefabrication is around $2 \%$ or lower by weight. This proves the orthodox that prefabrication in a factory environment is more conducive to waste reduction than the traditional cast in-situ construction manner. However, transporting the components adds cost and simultaneously increases the risk of waste generation. This study provides insights into understanding construction waste reduction through offshore prefabrication from a holistic view.
\end{abstract}

Keywords: Waste management; offshore prefabrication; international supply chain; Hong Kong

\section{Introduction}

In spite of its significant contribution to built environment development, construction is also perceived as a contributor to the degradation of environment (Bossink and Brouwers, 1996; Poon et

\footnotetext{
${ }^{1}$ Assistant Professor, Department of Real Estate and Construction, Faculty of Architecture, The University of Hong Kong, Pokfulam, Hong Kong. Email: wilsonlu@hku.hk

${ }^{2}$ Associate Professor, School of Economics and Management, Southwest Jiaotong University, Chengdu, Sichuan, 610031, China. Email: yuan@swjtu.edu.cn
} 
al., 2004a). Amongst the many factors such as dust, greenhouse gas emissions, noise pollution and consumption of non-renewable natural resources, construction waste is a major culprit. For example, historically the UK construction waste consumed more than 50\% of the overall landfill volume (Ferguson et al., 1995) and 70 million tons of construction waste was discarded annually (Sealey et al., 2001). Similarly, the US construction industry was reported to generate over 100 million tons of construction waste per annum (Mills et al., 1999) and approximately $29 \%$ of the solid waste in the USA was from the construction sector (Rogoff and Williams, 1994). In Australia, construction activities generated 20-30\% of all the waste entering landfills (Craven et al., 1994). In Hong Kong, the latest statistics on solid waste ending up at landfills reached 13,458 tons per day in 2011, of which 25\% was construction waste (EPD, 2012). Disposal of waste in landfills has led to extensive amounts of air, water and soil pollution due to the production of $\mathrm{CO}_{2}$ and methane from anaerobic degradation of the waste (Yuan et al., 2013; Lu and Tam, 2013).

How to minimize construction waste effectively has been a challenging issue receiving worldwide attention (e.g. Skoyles, 1976; Bossink and Brouwers, 1996; Craighill and Powell, 1999; Poon et al., 2001a; Tam, 2008; Lu et al., 2011). Amongst the various waste management strategies, prefabrication has been increasingly advocated. Prefabrication refers to structures or components of structures prefabricated at a different location other than the construction site, e.g. individual modules of a building are made in a factory and then transported to construction sites for final assembly (Gibb, 1999). Sometimes, this is entitled "offsite construction" or "industrialized building”, an idea borrowed from manufacture, generally taking place at a specialized facility (e.g. an assembly line) in which various materials are combined to form a distinct component of a larger installation (CIRIA, 1999). It has been commonly recognized that benefits of using construction prefabrication include reductions in cost, time, defects, health and safety risks, and a consequent increase in quality, predictability, whole-life performance and profitability (Gibb, 1999; Sparksman et al., 1999; Housing Forum, 2002; Parry et al., 2003; Venables et al., 2004).

Researchers have endeavored to ascertain the waste reduction potential of using prefabrication. For instance, Tam et al. (2007) conducted one of the early studies in Hong Kong finding that construction waste could be minimized up to $84.7 \%$ if prefabrication is applied. Jaillon and Poon (2009) conducted a comprehensive review of the evolution of prefabricated residential building systems in Hong Kong in both the public and private sectors. Their findings revealed a greater extent of prefabrication usage in terms of volumes and types of precast elements adopted. They also investigated the sustainable construction aspects (i.e., environmental, economic and social benefits) of using prefabrication in dense urban environment by taking Hong Kong as an example (Jaillon and Poon, 2008). Specifically, they tried to quantify the waste reduction potential of using prefabrication in building construction in Hong Kong, and found that construction waste reduction 
is one of the major benefits when using prefabrication compared with conventional construction; the average wastage reduction level was reported to be approximately $52 \%$ when adopting prefabrication (Jaillon et al., 2009).

Nevertheless, by taking on-site components assembly as a point of departure, their research design omitted of the upstream processes of prefabrication including manufacture and transportation of precast components. They compared prefabrication with traditional cast in-situ construction without fully considering the upstream processes, or in other words, the "cradle-to-site" processes, which could also result in construction waste. It has been understood that construction waste from precast concrete manufacture could be reduced in a factory environment, but to what extent it is really achieved and how transportation and storage of the components induce construction waste is not clear. Such enquiries are probably more complicated in a setting where precast components are manufactured offshore (such as in the PRDR) and transported to remote construction sites (such as in Hong Kong). This is called offshore prefabrication, which is not unique in the Hong Kong PRDR setting but has been widely practiced by firms in some advanced economies (Kedia and Mukherjee, 2009).

The aim of this study is to investigate the manufacture and cross-border transportation processes towards a life cycle assessment (LCA) of waste reduction potentials of using prefabrication construction. It allows a holistic understanding of waste management along the entire supply chain. Against a theoretical backdrop of LCA, this study conducted case studies in three medium-to-large scale PRDR prefabrication yards that supply precast components to Hong Kong. Although the study is undertaken in Hong Kong and the PRDR as a unique socio-economic background, there are similarities to other offshore supply chain settings such as Singapore-Malaysia, Europe-China, and the US-China.

\section{Research Methodology}

Life cycle analysis (LCA) is a technique that has been widely used to evaluate the environmental impacts throughout a product's life cycle, ranging from raw material acquisition, production and use phases, to final waste disposal (ISO, 2006). Finnveden et al. (2009) pointed out that the comprehensive scope of LCA is useful in order to avoid problem-shifting, for example, from one phase of the life cycle to another, from one region to another, or from one environmental problem to another. LCA is thus considered an ideal approach for holistically assessing waste reduction potential throughout the whole process of offshore prefabrication. This resonates with European Commission Communication recommending that LCA methodology (ISO 14040-44, 2006a,b) should be used jointly with the waste hierarchy such as reduction, reuse, and recycling. Despite that 
the applications of LCA to the environmental assessment of municipal solid waste (MSW) management have been prolific [e.g., Bovea et al. (2010), Buttol et al. (2007), Cherubini et al. (2009), Khoo (2010), Kim and Kim (2010), Niskanen et al. (2009), and Tunesi (2011)], Mercante et al. (2012) reported that LCA research in construction waste management is just beginning and not comparable with those reported in MSW management.

According to the ISO 14040 and 14044 standards, LCA is carried out in four distinct phases: (a) goal and scope definition; (b) life cycle inventory analysis; (c) impact assessment; and (d) interpretation. Owing to the sluggish development and erratic data availability in LCA of offshore prefabrication, this study focuses on the first two steps to define the goal and scope, and develop a flow model of the prefabrication system, based on which a more in-depth life cycle inventory analysis and impact assessment can be conducted accordingly by filling data when it is available. The study therefore must first draw a full picture of the supply chain of the offshore prefabrication for precast concrete components.

Three case studies were conducted to obtain data for describing offshore concrete prefabrication, with a view to identifying construction waste generated throughout the process. Case studies allow the exploration and understanding of complex issues based on primary data. It is considered a robust research method, particularly when a holistic and in-depth investigation is required (Yin, 1994). Under the umbrella of case study, various research methods such as interviews, focus group meetings, and participatory or non-participatory observations can be organized in a systematic way to understand the issue under study. In the PRDR there are nine sizable prefabrication yards that are mainly responsible for supplying precast concrete components to Hong Kong (see Table 1). Most of them are subsidiaries set up by main contractors or construction clients operating in Hong Kong. These yards provide internal supply to their parent companies. Two case studies were conducted from companies listed in Table 1 and one case study was carried out in a smaller company that supplies both the Hong Kong and PRDR construction markets. In each case, 3-7 researchers were involved. The studies started with interviews with senior personnel in each company. A semistructured open-ended discussion approach was used. A total of 8 questions (see Table 2) were presented and addressed in each of the interview sessions. It did not necessarily occur that the interviews strictly followed the questions listed. Rather, interviewees were encouraged to talk in more detail if they perceived that some aspects of particular importance should be clarified or stated. After the individual interviews, group discussions were carried out with the interviewees to further affirm their responses. Following the discussions, non-participatory observation was conducted in each of the prefabrication manufacture yards to understand how precast concrete components were manufactured in a factory environment. The information sources are summarized in Table 3. 
Table 1: Profile of prefabrications companies in PRD in supplying Hong Kong

\begin{tabular}{|l|l|l|l|}
\hline No. & $\begin{array}{l}\text { Company } \\
\text { names }\end{array}$ & $\begin{array}{l}\text { Factory area } \\
\mathbf{( 1 0 , 0 0 0} \mathbf{~ m}^{\mathbf{2}} \mathbf{)}\end{array}$ & Major clients \\
\hline 1 & A & 5 & Private, public housing projects and infrastructure \\
\hline 2 & B & 8 & Private housing projects and infrastructure \\
\hline 3 & C & 6 & Private, public housing projects \\
\hline 4 & D & 5 & Private, public housing projects \\
\hline 5 & E & 5 & Private housing projects \\
\hline 6 & F & 6 & Private housing projects \\
\hline 7 & G & 20 & Private housing projects and infrastructure \\
\hline 8 & H & 5 & Public housing projects \\
\hline 9 & I & 10 & Macau Private housing projects and Hong Kong infrastructure \\
\hline
\end{tabular}

Table 2: Interview questions

\begin{tabular}{|l|l|}
\hline Q1 & What are the offshore prefabrication plants/companies in the PRD? \\
\hline Q2 & $\begin{array}{l}\text { What is the total volume of prefabricated building components imported to Hong Kong over the } \\
\text { past years? }\end{array}$ \\
\hline Q3 & $\begin{array}{l}\text { What are the major types of prefabricated building components currently applied in Hong Kong } \\
\text { construction industry? }\end{array}$ \\
\hline Q4 & $\begin{array}{l}\text { What are the major wastes generated in the prefabrication process? And what is the waste } \\
\text { generation rate (WGR) for each of the waste materials arisen? }\end{array}$ \\
\hline Q5 & What are the major waste minimization measures adopted in prefabrication? \\
\hline Q6 & $\begin{array}{l}\text { How are the prefabricated building components transported from Shenzhen to Hong Kong? How } \\
\text { much is the transportation cost? }\end{array}$ \\
\hline Q7 & $\begin{array}{l}\text { Who will be responsible for any damage in transportation? What is the damage rate? How the } \\
\text { damaged components will be processed, treating as waste or being recycled to a certain degree? }\end{array}$ \\
\hline Q8 & $\begin{array}{l}\text { What is the coordination mechanism between the client, the prefabrication plant/company, and the } \\
\text { transport company? }\end{array}$ \\
\hline
\end{tabular}

Table 3: Basic information of the case studies

\begin{tabular}{|c|c|c|}
\hline \multicolumn{3}{|c|}{ Case 1 with Company A } \\
\hline Interviewees & - & $\begin{array}{l}\text { The vice-manager (responsible for the overall planning and development of the } \\
\text { prefabrication manufacturing company) } \\
\text { The chief engineer (in charge of the Research \& Development Center of the } \\
\text { company) } \\
\text { The technical engineer (familiar with the company's building prefabrication } \\
\text { products) }\end{array}$ \\
\hline Group discussions & \multicolumn{2}{|r|}{30 minutes } \\
\hline $\begin{array}{l}\text { Non-participation } \\
\text { observations }\end{array}$ & \multicolumn{2}{|c|}{40 minutes } \\
\hline \multicolumn{3}{|c|}{ Case 2 with Company D } \\
\hline Interviewees & & $\begin{array}{l}\text { The owner (responsible for the overall development of the company, has more } \\
\text { than } 30 \text { years' experience in the area, and is setting up other factories in China) }\end{array}$ \\
\hline
\end{tabular}




\begin{tabular}{|l|l|}
\hline & $\bullet \quad$ The technical director (with a claimed 50 years' experience) \\
\hline Group discussions & 30 minutes \\
\hline $\begin{array}{l}\text { Non-participation } \\
\text { observations }\end{array}$ & 50 minutes \\
\hline Case 3 with Company X \\
\hline Interviewees & $\bullet \begin{array}{l}\text { The general manager (Chief engineer of the mother company and the general } \\
\text { manager in this prefabrication company, young but aggressive in business) } \\
\text { The vice-manager (responsible for daily operation of this prefabrication } \\
\text { company) }\end{array}$ \\
\hline $\begin{array}{l}\text { Group discussions } \\
\text { observations }\end{array}$ & \begin{tabular}{l}
30 minutes \\
\hline
\end{tabular} \\
\hline
\end{tabular}

The case studies generated good first-hand qualitative data for understanding construction waste management in the offshore prefabrication supply chain. The data was further triangulated with the data obtained from various sources including the Hong Kong Census and Statistics Department (C\&SD), Guangdong Province Yearbook, the Buildings Department, the Lands Department, and the Hong Kong Housing Authority (HKHA). Content analysis approach was applied to triangulate the understanding from the previous literature survey with the qualitative data acquired from the case studies.

\section{Findings, analyses and discussions}

\subsection{Prefabrication in Hong Kong}

Prefabrication technologies are not new to Hong Kong. Prefabricated buildings were first developed along with the public housing programs in Hong Kong, e.g. Home Ownership Scheme (HOS). In the mid-1980s, prefabrication combined with standard modular design was introduced in public housing projects (Mak, 1999). Major precast elements used include precast facades, staircases, parapets, partition walls, semi-precast slabs and, more recently, volumetric precast bathrooms and kitchens. In 2002, precast components accounted for approximately $17 \%$ of the total concrete volume used in public housing projects (Chiang et al., 2006). In 2005, a pilot project extended the use of precast components to 65\% including the use of precast kitchen and structural walls (HKHA, 2005). This is phenomenal given that HKHA has a stock of about 700,000 flats in over 1,100 domestic buildings, and an average production of about 15,000 new flats per year (Fung, 2010). In addition, according to HKHA's forecast, there will be in total 77,800 public housing flats to be 
produced from 2012/13 to 2016/17 (HKHA, 2012). Prefabrication is expected to continue to flourish in the public housing sector.

In contrast, the adoption of prefabrication in the private housing sector has been sluggish. The reasons are multifold. Cost is a major problem. Prefabrication is slightly more expensive than conventional cast in-site construction. Jaillon and Poon (2008) reported in a case study that the unit cost of precast construction is approximately $2 \%$ higher than that of conventional cast in-situ construction method. Our interviewee reflected that the cost for prefabrication is HK\$2560-2625/ $\mathrm{m}^{3}$ while the unit cost for conventional construction ${ }^{3}$ is around $H K \$ 2250 / \mathrm{m}^{3}$. Flexibility is another issue (Ho, 2001; Ting, 1997; Tam, 2007). Design change is widespread in the Hong Kong construction sector, particularly in those fast-tracked projects responding to the changing market demand. However, design change is the enemy of prefabrication, which benefits from economies of scale through repetition and mass production. Moreover, on the supply side, the initial cost for setting up a prefabrication yard is relatively high. Private companies thus hesitate to enter this arena unless stable demand from clients is foreseen.

The situation has changed since early 2000 when Hong Kong issued a series of policies to encourage sustainable construction through applying prefabricated building components in projects. In a report by the Construction Industry Review Committee (CIRC), the wider use of prefabrication, coupled with the use of standardized and modular components, was proposed as a primary strategy for enhancing the environmental friendliness of the Hong Kong construction industry (CIRC, 2001). It was also recommended that the HKHA should take the leading role in promoting the wider use of prefabrication, while the private sector's capacities of applying prefabrication should be enhanced through training, promulgation of related guidelines and codes, and Research \& Development (CIRC, 2001). Following the report, the Joint Practice Notes (JPN) 1 and 2 were jointly issued by the Hong Kong Buildings Department, Lands Department, and Planning Department (BD, 2001; 2002), whereby building developers could receive gross floor area exemptions if green building technologies and prefabricated building components such as balconies, sunshades, and prefabricated external walls were adopted ${ }^{4}$. A more comprehensive review of the evolution of prefabricated residential building systems in Hong Kong public and private sectors can be found in Jaillon and Poon (2009).

\footnotetext{
${ }^{3}$ The interviewee gave the rate in Chinese currency (RMB), which has been transferred to HK\$ on the exchange rate that $1 \mathrm{RMB}=1.2656 \mathrm{HK} \$$. Transaction of prefabrication components is by volume $\left(\mathrm{m}^{3}\right)$ or weight (ton) and there is a rule-of-thumb formula that 2.4 ton $=1 \mathrm{~m}^{3}$.

${ }^{4}$ The Departments have updated the JPNs $1 \& 2$ in 2011. At the core of the updates is that an overall cap of $10 \%$ GFA exemptions for a number of features which still qualify for concession is imposed.
} 


\subsection{Offshore prefabrication in the Hong Kong - PRDR setting}

Moving the Hong Kong prefabrication sector to an offshore area (e.g. the PRDR) is a natural response to the changing socio-economic background in the region. Hong Kong imports almost all materials for construction use. Mainland China is one of the major material suppliers because China is able to offer a full spectrum of materials owing to its resource availability and strong manufacture capability. Offshore prefabrication makes it possible to exploit cheap materials. This echoes the findings of $\mathrm{Lu}$ et al. (2009) that more and more overseas construction companies are sharing China's plentiful and cheap construction materials by global purchasing. Moreover, construction is a traditionally labor-intensive industry. Owing to many reasons such as an ageing population (CSD, 2010), booming local construction market (e.g. ten mega-infrastructure projects), and a poor image of the construction industry (CIC, 2011), there is a severe labor shortage in the Hong Kong construction industry on the one hand while it is difficult to open the market to Mainland labor on the other. Labor cost is becoming extremely high. A frequently cited example is that the average daily wages for a bar bender and fixer, a mason, and a bamboo scaffolder are HK\$1295.5, HK\$1247.5, and HK\$1147.0, respectively (CSD, 2012). PRDR prefabrication makes it possible to exploit a cheap and abundant labor force. The amenable trading arrangements between the two regions further nurture the offshore prefabrication sector. In addition, a prefabrication factory requires a relatively large area for manufacturing and storing precast concrete components (see Table 1). It is difficult to find such space in Hong Kong due to its very limited land resources. Siting the factories in the PRDR has been a preferred choice. All these socio-economic factors have driven both Hong Kong and PRDR governments to direct contractors' attention toward residing the offshore prefabrication industry in the PRDR of mainland China.

As a matter of fact, the whole prefabrication sector in Hong Kong has been moved to the offshore areas in the PRDR such as Shenzhen, Dongguan, Huizhou, Zhongshan, and Shunde. Table 1 (earlier) shows that more than half of the companies have hitherto supplied prefabricated building components to the private housing sector in Hong Kong. Yet, it is difficult to find statistics for drawing the full picture of the offshore prefabrication sector precisely. In official statistics, prefabricated building components are treated as bulk stock mixing with other imported and exported goods. In the first case study, the chief engineer provided the research team with the amounts of prefabricated building components that have been produced and exported by his company over the past five years. It can be seen from Table 4 that an average of 36,580.86 $\mathrm{m}^{3}$ of prefabricated building components has been produced and delivered to Hong Kong construction sites annually. 


\begin{tabular}{|l|l|l|l|l|l|l|}
\hline & 2007 & 2008 & 2009 & 2010 & 2011 & Average \\
\hline $\begin{array}{l}\text { Volume } \\
(\mathrm{m} 3)\end{array}$ & 41377.25 & 49969.92 & 20898.16 & 32142.74 & 38516.20 & 36580.86 \\
\hline
\end{tabular}

\subsection{Upstream processes of prefabrication construction in the PRDR and their waste reduction}

Based on the case studies, the flow model of the offshore prefabrication system and its system boundary for LCA of waste reduction can be illustrated in Fig. 1. In this study, we called material procurement, manufacturing, storage and transportation of prefabricated components the upstream processes of offshore prefabrication. They mainly take place in the PRDR with local suppliers, manufacturers, customs officers, and local and offshore transporters involved.

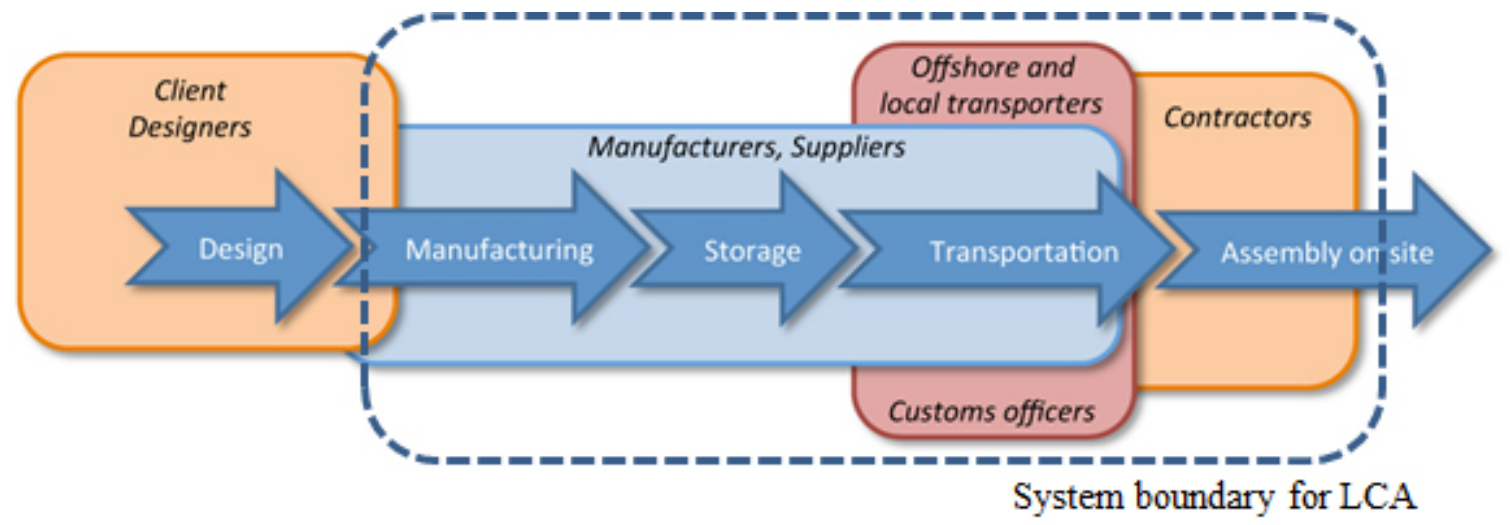

Fig. 1 The offshore prefabrication housing processes

As argued previously, these upstream processes can also cause construction waste, which has largely been neglected by previous studies though. The case studies revealed that construction waste management starts from material purchasing and storage. Materials such as sand, gravel, cement, and rebar are procured from various suppliers. It should be conducted with great care otherwise counterfeit materials might be procured, which in turn will lead to construction waste. Fig. 2 shows that materials such as sand, gravel, and reinforcement are pre-treated, piled and covered carefully to avoid waste generation. 

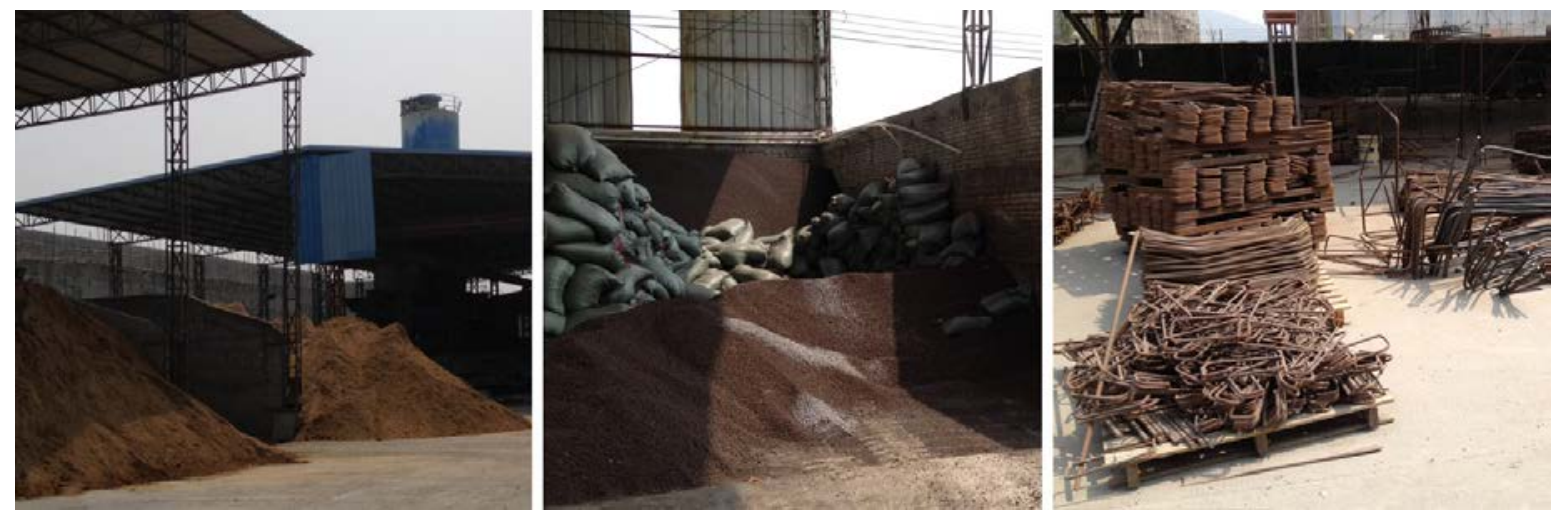

Fig. 2 Pre-treatment and storage of construction materials in a prefabrication yard

The concrete needs to be mixed and therefore a concrete blending tower is often spotted in a prefabrication yard (see Fig. 3). The rebar will be cut, bended, and fixed for different usages such as beams, partition walls (dry walls), semi-precast slabs, columns and staircases. The more contemporary uses are facades, volumetric kitchens and bathrooms where components such as ducts, sinks, windows and tiles are prefabricated. The two major types of materials including steel bars and concrete will be manufactured on the production line, which is mainly formed by thousands of steel modules, and facilitated by a large number of gantry cranes (see Fig. 3). Hence, the process is different from traditional cast in-situ construction where timber formwork and falsework have been adopted and ended up as construction waste (Poon et al., 2004). Tam et al. (2007) reported that the major construction materials forming waste are concrete, reinforcement, formwork, brick/block, and tiles from various trades. These were spotted in the surveyed cases (see Fig. 4) but the volumes are much less than that found by Tam et al. (2007). Even the surplus concrete from a component can be casted to blocks (see Fig. 4) if it has not been used in other modules immediately. Reinforcement waste does exist but it can be recycled (see Fig. 4). There is no timber waste. Tiles could be a major waste source in conventional construction (Tam et al., 2007). But in prefabrication construction they are pre-laid in the factory and consequently the quality is much better and the waste generation is truly minimized.
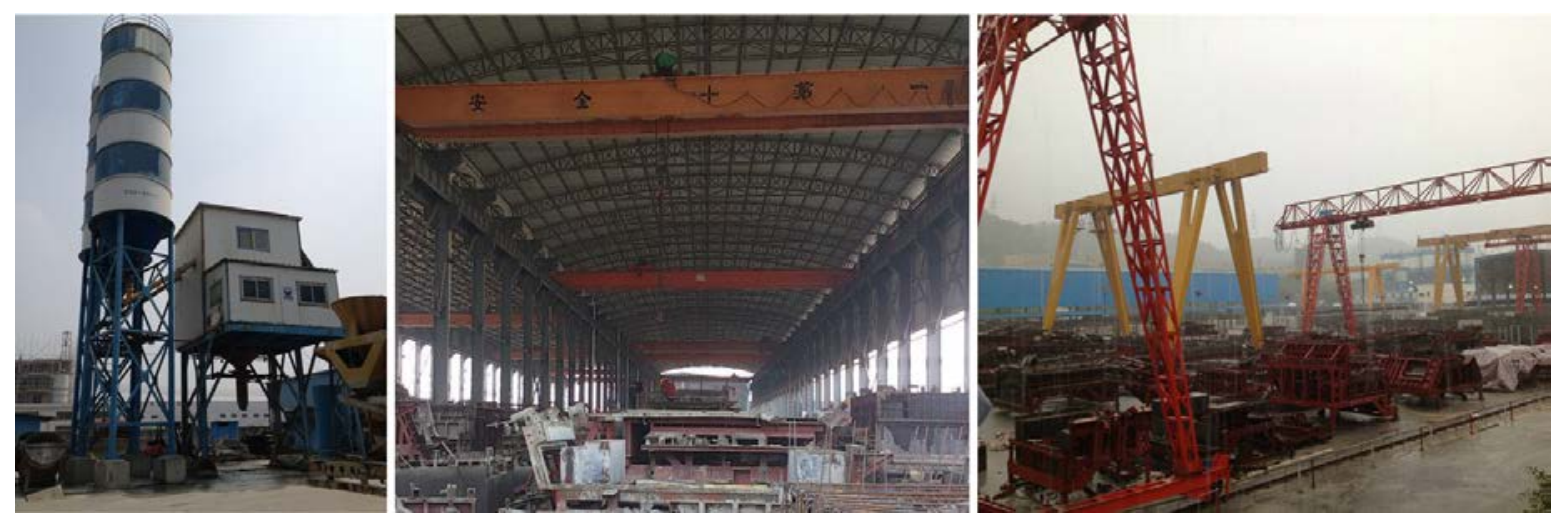

Fig. 3 Manufacturing process in prefabrication construction 

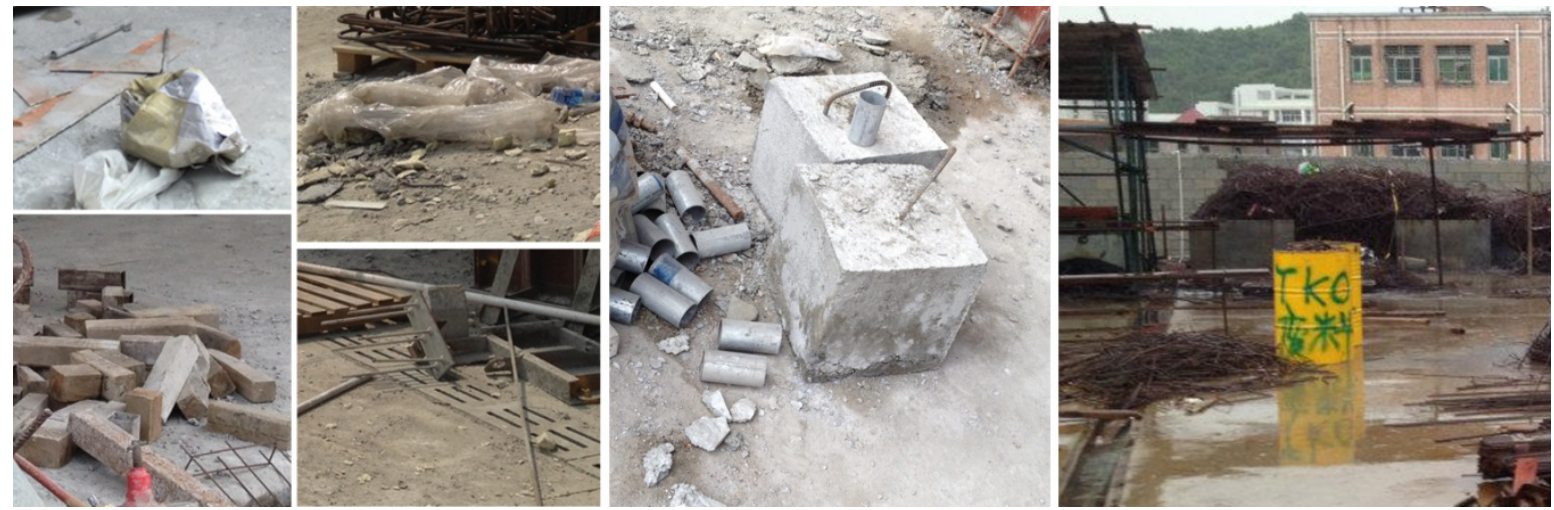

Fig. 4 Construction waste generated from the manufacturing process of prefabrication construction

Finding enough space for temporarily storing the large amount of prefabricated components is often challenging (see Fig. 5). For example, one of the companies is trying to set up a company in another satellite city in the PRDR mainly because the current site is almost full. The storage process needs to be handled with great care. Otherwise it will cause significant construction waste as the concrete has hardened and all the materials have been fabricated together. Unlike construction sites which are often of confined areas, a prefabrication yard is often even, flat and spacious for handling and storing building components. As a result, the wastage level in this process can be reduced to nearly zero. Quality inspection by the client is conducted regularly at this stage to proactively prevent counterfeit components and construction waste.
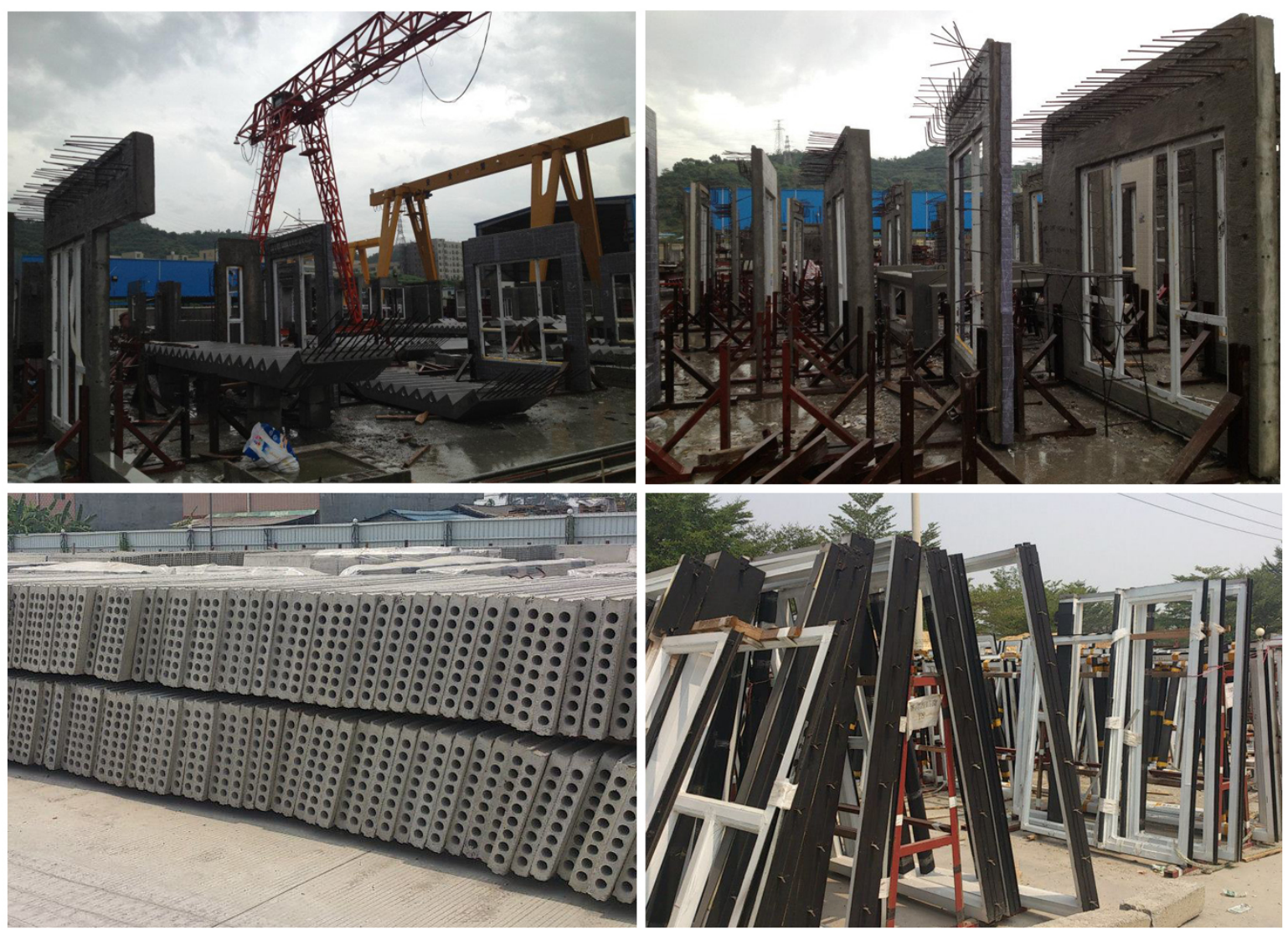
Fig. 5 Storage of building components in prefabrication construction

Transportation of prefabricated building components to Hong Kong is often outsourced to professional logistics companies. According to the interview, the prefabricated components are mostly transported to Hong Kong by lorries (see Fig. 6). The logistics companies are responsible for loading, fastening, and unloading of the prefabricated building components, as well as custom clearance. Instead of transporting the components to the construction sites using a Just-In-Time (JIT) system, the logistics companies place them in their warehouses in Lok Ma Chau, which is a large spare area just very close to the Hong Kong-Shenzhen border. We call this a semi-JIT system, whereby the prefabricated components can be buffered in warehouses to guarantee a stable supply to the sites in view of the different holiday arrangements between Hong Kong and Shenzhen, and the narrow and congested streets in Hong Kong. This does, however, entail double-handling.
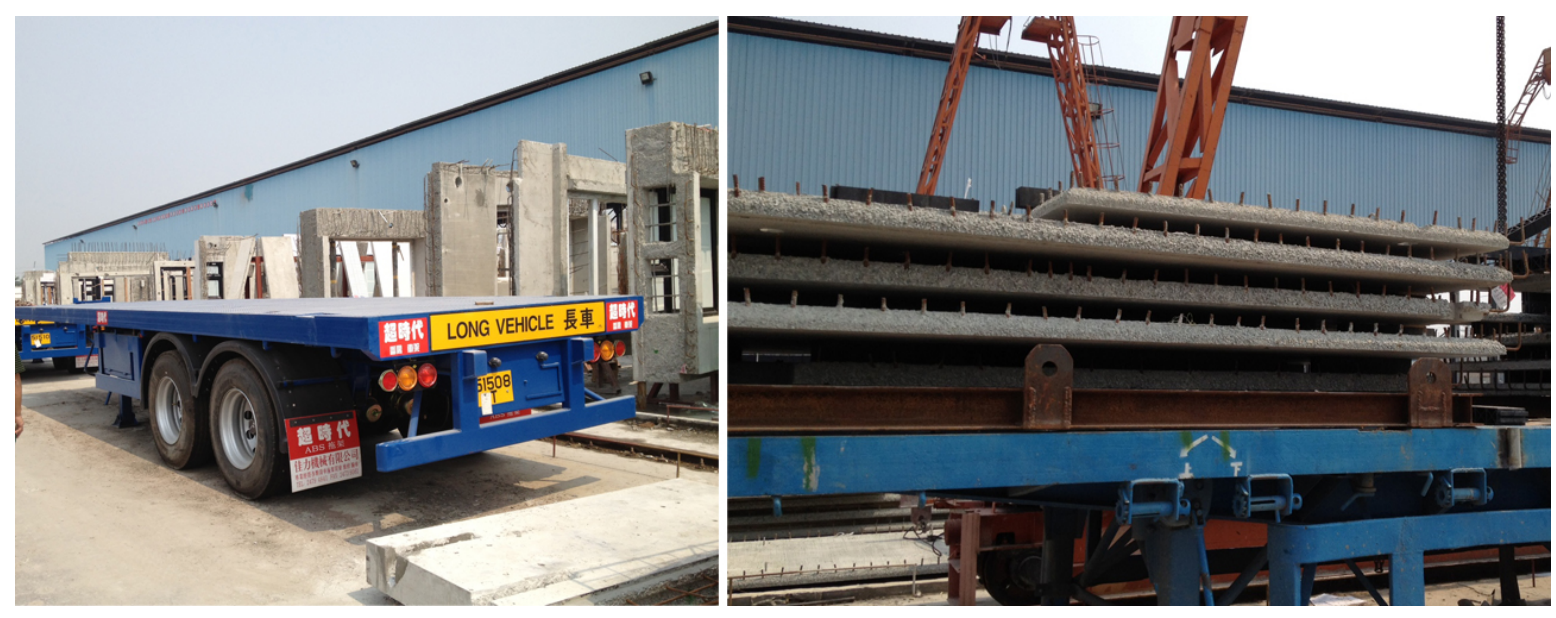

Fig. 6 Transportation of building components in prefabrication construction

An interviewee estimated that the average cost of transporting prefabricated building components from the surveyed plant to Hong Kong construction sites is approximately HK\$253 per ton. Another interviewee reflected that transportation costs HK\$6,000 per lorry and overall it takes up around $18-20 \%$ of the total cost. It is found from the case studies that normally the transporter will take initiatives to prevent the products from being damaged or broken. Since mostly the components can be delivered to the client successfully owing to a professional logistic and supply chain sector in Hong Kong, the interviewees stated that the prefabrication company will not insure the transported products. However, environmental pressures have been increasingly seen in both Hong Kong and PRDR. As a result, factories will work with the logistics companies to reduce potential nuisance to local residents. The interviewees argued that rarely do components get damaged in the process of transportation, according to their experiences in the past few years. In case of any damage during the transportation, the seller (i.e. the prefabrication plant/company) will take remedial actions 
immediately after the accident. The damage will be handled based on the extent to which they are damaged. The interviewees stated that for those slightly damaged prefabricated components, remedial measures will be taken by workers of the factory to repair them. The remediation will be done in a very short period and does not affect the prefabrication components' normal functions. For those severely damaged components, they cannot be used in the structures anymore and will end up as waste to be recycled or disposed of in landfill in Hong Kong. The prefabrication companies will be in charge of dealing with related costs and processes.

\subsection{Waste reduction potential in offshore prefabrication}

Alongside the flow model of the offshore prefabrication system (see Fig. 1), an inventory analysis and an impact assessment can be conducted to understand the potential environmental impacts, with a focus on construction waste reduction in this study. However, it was also noticed that the managers are cautious in providing specific data (e.g. logistic cost), probably for fearing of leaking business secrets. This makes it impossible to obtain access to the manufacture records of each company, only with which the waste reduction potential of using prefabrication can be precisely quantified. All interviewees reflected that waste minimization in prefabrication is much easier to be performed than that on construction sites. However, when it comes to particular waste minimization measures, no sound ones have been suggested. The interviewees are further encouraged to estimate the waste generation rate (WGR) based on their experience. Surprisingly, three interviewees reflected that WGR is "nearly zero". It was observed in one of the cases that major waste materials generated from the prefabrication processes involved reinforcing steel bars, ceramic chips and material curing compound. But it is difficult for the interviewees to estimate the exact proportions of those wasted materials. The reasons could be that either they are reluctant to reveal the information, or the WGRs are so low that it has not triggered the managers' initiatives to deal with the waste systematically. But controlling materials and reducing waste is the goal of any manufacturing company. Encouragingly, the interviewees told us that there is a quality control system in place at the company level. With this system, wastage of major materials in prefabrication is strictly supervised and controlled. As estimated by two of the interviewees, the WGR of most raw materials used in manufacturing prefabricated building components is lower than $2 \%$ by weight.

Moreover, as reported by Tam et al. (2007) and Jaillon et al. (2009), the wastage level associated with the downstream process (i.e. precise components assembly on-site) of offshore prefabrication construction in Hong Kong ranges from 2-7\% from trade to trade. Thus, in total, the wastage level of using prefabrication throughout the whole life cycle ranges from $4 \%$ to $9 \%$. It can be generally concluded that the overall waste generation of offshore prefabrication is found to be much lower than that of conventional construction. Specifically, Tam et al. (2007) found that assembling precast 
building components on-site could achieve an overall waste reduction of $74-100 \%$ (here waste reduction of $100 \%$ means that a Zero Waste target is achieved) when compared with cast in-situ construction. Based on survey results from 14 building projects in Hong Kong, Jaillon et al. (2009) reported that prefabrication realized a waste reduction level of $57 \%$ for public projects and $23 \%$ for private projects. If the construction wastage level of prefabrication construction in Hong Kong is related to a wider community, for example, findings that the WGR ranged from 2-15\% by weight according to the amount purchased for 37 materials in the UK (Skoyles, 1976), and 3.275 to 8.791 $\mathrm{kg} / \mathrm{m}^{2}$ in Shenzhen (Lu et al., 2011), the comparison further affirms the statement that prefabrication in a factory environment is more conducive to waste reduction than conventional cast in-situ construction.

\section{Conclusions}

Prefabrication has been increasingly adopted worldwide for minimizing construction waste. In Hong Kong, moving the prefabrication companies to an offshore area (i.e. the PRDR of mainland China) has been a preferred response to the evolving socio-economic conditions particularly including environment degradation, labor and land shortage, and closer economic partnership between the regions. By putting it into this context, the waste reduction potential of using offshore prefabrication has been investigated by taking into account its upstream processes of manufacturing and transportation of precast components. Three prefabrication companies which located in the PRDR but supplied prefabricated building components for Hong Kong contractors are studied. It is found that prefabrication of concrete components in a factory environment is more conducive to waste reduction than traditional cast in-situ construction method. The waste generation rate in the upstream of offshore prefabrication (i.e. manufacturing and transporting prefabricated building components) is around $2 \%$ by weight or lower. Transportation of the building components not only adds to the cost and carbon emission burdens but also increases the risk of waste generation. However, handling with care, the overall waste reduction potential is higher than that in tradition construction method.

The study also has its limitations. The analyses could not be quantitative unless access to the factories' manufacturing records was enabled. A comparison of the records from various factories could lead to the identification of best waste management practice in offshore prefabrication but this is extremely difficult owing to self-guarded business secrets. The whole lifecycle thinking does make sense in encouraging considering waste generation through the prolonged logistic and supply chain that is increasingly seen in offshore construction. Future research is needed to explore the mechanism through which the cost and benefits of offshore prefabrication such as reduced construction waste and increased carbon emission can be shared. 


\section{Acknowledgements}

The work is jointly supported by the Hong Kong Research Grants Council (RGC), Public Policy Research (PPR) Scheme project (RGC Ref. HKU7016-PPR-11) and the National Natural Science Foundation of China (NSFC) project (No.: 71273219). Appreciation goes to the interviewees and their factories who have greatly helped in this research. Research postgraduates including Kevin Wong, Cong Liang, Rong Zhang and others from the University of Hong Kong are much appreciated for their help in the case studies.

\section{References}

Bossink AG, Brouwers HJH. Construction waste: quantification and source evaluation. ASCE Journal of Construction Engineering and Management 1996; 122 (1): 55-60.

Bovea MD and Powell JC. Alternative scenarios to meet the demands of sustainable waste management. Journal of Environmental Management 2006; 79:115-132.

Buildings Department. Joint Practice Notes No.1, Green and Innovative Buildings. The Hong Kong Special Administrative Region Government (HKSARG), Hong Kong; 2001.

Buildings Department. Joint Practice Notes No.2, Second Package of Incentives to Promote Green and Innovative Buildings. The Hong Kong Special Administrative Region Government (HKSARG), Hong Kong; 2002.

Buttol P, Masoni P, Bonoli A, Goldoni S, Belladonna V, Cavazzuti C. LCA of integrated MSW management systems: case study of the Bologna District. Waste Management 2007; 27:10591070

Census and Statistics Department. Hong Kong Population Projections 2010-2039. Census and Statistics Department; 2010.

Cherubini F, Bargigli S, Ulgiati S. Life cycle assessment (LCA) of waste management strategies: landfilling, sorting plant and incineration. Energy 2009; 34:2116-2123.

Chiang YH, Chan EHW, Lok LKL. Prefabrication and barriers to entry-a case study of public housing and institutional buildings in Hong Kong. Habitat International 2005; (28): 1-18.

CIRC. Construct for Excellence, Construction Industry Review Committee Report, Hong Kong; 2001.

CIRIA. Standardisation and pre-assembly adding value to construction projects. Report 176. CIRIA, London, UK; 1999.

Craighill A, Powell JC. A lifecycle assessment and evaluation of construction and demolition waste. CSERGE Working Paper WM 99-03; 1999.

Craven DJ, Okraglik HM, Eilenberg IM. Construction waste and a new design methodology. In: Kibert, C.J. (Ed.), Sustainable Construction. Center for Construction and Environment, Gainesville, FL, 1994; pp. 89-98. 
Ferguson J, Kermode N, Nash CL, Sketch WAJ, Huxford RP. Managing and Minimising Construction Waste: A Practical Guide. Institution of Civil Engineers, London; 1995.

Finnveden G, Hauschild MZ, Ekvall T, Guinée J, Heijungs R, Hellweg S, Koehler A, Pennington D, Suh S. Recent developments in life cycle assessment. Journal of Environmental Management 2009; 91(1): 1-21.

Gibb AGF. Offsite Fabrication: Prefabrication, Pre-assembly and Modularisation, Whittles, Caithness; 1999.

HKHA (Hong Kong Housing Authority). Annual Report 2004/2005, HKSARG, Hong Kong; 2005.

Ho OST. Construction waste management - a contractor's perspective. The Hong Kong Institute of Builders; 2001, July, 8-11.

Housing Forum. Homing in on Excellence: A Commentary on the Use of Offsite Fabrication Methods for the UK House building Industry. The Housing Forum, London; 2002.

ISO 14040. Environmental management. Life Cycle Assessment. Principles and Framework 2006a. European Committee for Standardization (CEN).

ISO 14044. Environmental management. Life Cycle Assessment. Requirements and guidelines 2006b. European Committee for Standardization (CEN).

ISO. ISO 14040 International Standard. In: Environmental Management -Life Cycle Assessment Principles and Framework. International Organisation for Standardization, Geneva, Switzerland; 2006.

Jaillon L, Poon CS, Chiang YH. Quantifying the waste reduction potential of using prefabrication in building construction in Hong Kong. Waste Management 2009; 29(1): 309-20.

Jaillon L, Poon CS. Sustainable construction aspects of using prefabrication in dense urban environment: a Hong Kong study. Construction Management and Economics 2008; 26(9): 953966.

Jaillon L, Poon CS. The evolution of prefabricated residential building systems in Hong Kong: A review of the public and the private sector. Automation in Construction 2009; 18: 239-248.

Kedia BL, Mukherjee D. Understanding offshoring: a research framework based on disintegration, location and externalization advantages. Journal of World Business 2009; 44: 250-261.

Kedia, BL, Mukherjee D. Understanding offshoring: A research framework based on disintegration, location and externalization advantages. Journal of World Business 2009; 44: 250-261.

Khoo H. Food waste conversion options in Singapore: environmental impacts based on an LCA perspective. Science of Total Environment 2010; 408(6):1367-1373.

Kim M, Kim J. Comparison through a LCA evaluation analysis of food waste disposal options from the perspective of global warming and resource recovery. Science of Total Environment 2010; 408(6): 3998-4006. 
Lu HW, Huang GH, He L, Zeng GM. An inexact dynamic optimization model for municipal solid waste management in association with greenhouse gas emission control. Journal of Environmental Management 2009; 90: 396-409.

Lu WS, Li H, Shen LY, Huang T. A SWOT analysis of Chinese construction companies in the global market. Journal of Management in Engineering 2009; 25(4): 166-176.

Lu WS, Yuan HP, Li JR, Hao JL, Mi XM, Ding ZK. An empirical investigation of construction and demolition waste generation rates in Shenzhen city, South China. Waste Management 2011; 31: 680-687.

Mak YW. Prefabrication and Industrialisation of Housing in Hong Kong. Master thesis, The Hong Kong Polytechnic University, Hong Kong; 1998.

Mercante IT, Bovea MD, Ibáñez-Forés V, Arena AP. Life cycle assessment of construction and demolition waste management systems: a Spanish case study. International Journal of Life Cycle Assessment, 2012; 17:232-241.

Mills TM, Showalter E, Jarman D. A cost-effective waste management plan. Cost Engineering 1999; 41(3): 35-43.

Niskanen A, Manfredi S, Christensen T, Anderson R. Environmental assessment of Ämmässuo Landfill (Finland) by means of LCA-modelling. Waste Management \& Research 2009; 27:542550

Ortiz O, Castells F, Sonnemann G. Sustainability in the construction industry: A review of recent developments based on LCA. Construction and Building Materials 2009; 23: $28-39$.

Parry T, Howlett C, Samuelsson-Brown G. Off Site Fabrication: UK Attitudes and Potential. Report 17356/1, BSRIA, Bracknell; 2003.

Poon CS, Yu ATW, Ng LH. A Guide for Managing and Minimizing Building and Demolition Waste. The Hong Kong Polytechnic University, Hong Kong; 2001.

Poon CS, Yu ATW, Wong SW, Cheung E. Management of construction waste in public housing projects in Hong Kong. Construction Management and Economics 2004; 22 (7): 675-689.

Rogoff MJ, Williams JF. Approaches to Implementing Solid Waste Recycling Facilities. Noyes, Park Ridge, NJ; 1994.

Sealey BJ, Phillips PS, Hill GJ. Waste management issues for the UK readymixed concrete industry. Resources, Conservation and Recycling 2001; 32 (3-4): 321-331.

Skoyles ER. Materials wastage - a misuse of resources. Building Research and Practice, 1, 232-243 (July/August 1976).

Sparksman G, Groak S, Gibb A, Neale R. Standardisation and Pre-assembly: Adding Value to Construction Projects, CIRIA, London; 1999.

Tam VWY. On the effectiveness in implementing a waste-management plan method in construction. Waste Management 2008; 28 (6): 1072-1080. 
Tam WWY, Tam CM, Zeng SX, Ng WCY. Towards adoption of prefabrication in construction. Building and Environment 2007; 42: 3642-3654.

Ting YH. The economic implications of subcontracting practice on building prefabrication. Automation in Construction 1997; 6(3): 163-74.

Tunesi S. LCA of local strategies for energy recovery from waste in England, applied to a large municipal flow. Waste Management 2011;31(3):561-571

Venables T, Barlow J, Gann D. Manufacturing Excellence: UK Capacity in Offsite Manufacturing, The Housing Forum, London; 2004.

Wong F, Tang YT. Comparative embodied carbon analysis of the prefabrication elements compared with in-situ elements in residential building development of Hong Kong. World Academy of Science, Engineering and Technology 2012; 62: 161-166.

Yin RK. Case Study Research: Design and Methods, Beverly Hills, Sage Publications; 1984.

Yuan HP, Lu WS, Hao JL. The evolution of construction waste sorting on-site. Renewable and Sustainable Energy Reviews 2013; 20: 483-490. 